\title{
The Neuroprotective Effect of Zingiber cassumunar Roxb. Extract on LPS-Induced Neuronal Cell Loss and Astroglial Activation within the Hippocampus
}

\author{
Ratchaniporn Kongsui $\mathbb{D}^{1},{ }^{1}$ Napatr Sriraksa, ${ }^{1}$ and Sitthisak Thongrong ${ }^{2}$ \\ ${ }^{1}$ Division of Physiology, School of Medical Sciences, University of Phayao, Phayao 56000, Thailand \\ ${ }^{2}$ Division of Anatomy, School of Medical Sciences, University of Phayao, Phayao 56000, Thailand \\ Correspondence should be addressed to Ratchaniporn Kongsui; rat_nick@hotmail.com
}

Received 9 January 2020; Revised 10 May 2020; Accepted 15 May 2020; Published 27 May 2020

Academic Editor: Kenjiro Ono

Copyright (c) 2020 Ratchaniporn Kongsui et al. This is an open access article distributed under the Creative Commons Attribution License, which permits unrestricted use, distribution, and reproduction in any medium, provided the original work is properly cited.

\begin{abstract}
The systemic administration of lipopolysaccharide (LPS) has been recognized to induce neuroinflammation which plays a significant role in the pathogenesis of neurodegenerative diseases such as Alzheimer's disease and Parkinson's disease. In this study, we aimed to determine the protective effect of Zingiber cassumunar (Z. cassumunar) or Phlai (in Thai) against LPSinduced neuronal cell loss and the upregulation of glial fibrillary acidic protein (GFAP) of astrocytes in the hippocampus. Adult male Wistar rats were orally administered with $Z$. cassumunar extract at various doses (50, 100, and $200 \mathrm{mg} / \mathrm{kg}$ body weight) for 14 days before a single injection of LPS $(250 \mu \mathrm{g} / \mathrm{kg} / \mathrm{i} . \mathrm{p}$.). The results indicated that LPS-treated animals exhibited neuronal cell loss and the activation of astrocytes and also increased proinflammatory cytokine interleukin- (IL-) $1 \beta$ in the hippocampus. Pretreatment with $Z$. cassumunar markedly reduced neuronal cell loss in the hippocampus. In addition, $Z$. cassumunar extract at a dose of $200 \mathrm{mg} / \mathrm{kg}$ BW significantly suppressed the inflammatory response by reducing the expression of GFAP and IL- $1 \beta$ in the hippocampus. Therefore, the results suggested that $Z$. cassumunar extract might be valuable as a neuroprotective agent in neuroinflammation-induced brain damage. However, further investigations are essential to validate the possible active ingredients and mechanisms of its neuroprotective effect.
\end{abstract}

\section{Introduction}

Neuroinflammation plays an important role in the pathogenesis of various neurodegenerative diseases including Alzheimer's disease (AD), Parkinson's disease (PD), Huntington's disease, and dementia [1-3]. In addition, neuroinflammation has implicated in other brain pathological conditions including depression and cerebral ischemia [4]. In the central nervous system (CNS), microglia and astrocytes are displayed as immune effector cells that are involved in neuroinflammation [5, 6]. Activation of the peripheral immune system primes increasing of cytokine levels that are transported into the CNS-stimulating astrocytes and microglial cells [7]. Several studies have provided the evidence that the activation of these glial cells in responding to immune stimuli produces various inflammatory cytokines such as tumor necrosis factor- (TNF-) $\alpha$, interleukin- (IL-) $1 \beta$, and nitric oxide (NO) that trigger neuronal damage [8-10] and cognitive impairment $[11,12]$. Lipopolysaccharide (LPS) is an endotoxin, which is a component of the outer cell wall of gram-negative bacteria, and widely used for the experimental model of neuroinflammation associated with neurodegeneration $[13,14]$. Preclinical studies have revealed that intraperitoneal injection of LPS can result in the increased production of inflammatory mediators in the brain, leading to neuronal loss and learning and memory impairments [11, 15-17]. Moreover, LPS also induces sickness-like behaviors including weight loss, decreased locomotion, and 
increased anxiety [18-20].

To date, there is a growing interest in the neuroprotective effect of herbal medicinal plants mainly against brain damage such as ginger [21, 22], ginkgo [23], ginseng [24], and curcumin $[25,26]$. Zingiber cassumunar (Z. cassumunar), a plant in the Zingiberaceae family, is commonly known as "Phlai" in Thai. This medicinal plant consisting of underground rhizomes that have been used for traditional treatment to treat various illnesses such as inflammation, muscle and joint problems, skin diseases, and wound healing [27]. Z. cassumunar has been reported to have biological properties including anti-inflammation [28], antioxidant [29], and antiallergic [30]. However, none have investigated the neuroprotective effect of $Z$. cassumunar on animal models of neuroinflammation induced by LPS. Therefore, the present study was designed to examine whether pretreatment with $Z$. cassumunar extract would be effective for neuroprotection against LPS-induced neuronal cell loss by inhibiting astroglial activation in the hippocampus.

\section{Materials and Methods}

2.1. Animals. Adult male Wistar rats aged 8 weeks were obtained from the Nomura Siam International Co., Ltd. (Bangkok, Thailand) and were allowed a week for acclimatization prior to the commencement of experimentation. All animals were housed and maintained on a $12: 12 \mathrm{~h}$ lightdark cycle in a constant temperature $\left(21 \pm 1^{\circ} \mathrm{C}\right)$ and humidity room with food and water available ad libitum. All procedures were approved by the Ethics Committee of the Laboratory Animal Research Center, University of Phayao (approval no. 600104022 ).

2.2. Plant Materials and Preparation. The fresh rhizomes of Z. cassumunar were bought from a local market in Muang District, Phayao Province, Thailand. The extraction was conducted using the method described previously by Wong-anan et al. [31]. Briefly, the samples were cleaned and cut to small pieces then dried with hot air oven at $60^{\circ} \mathrm{C}$ for $48 \mathrm{~h}$. Dried samples $(4.5 \mathrm{~kg}$ of $Z$. cassumunar) were ground and extracted with $95 \% v / v$ ethanol by maceration. The ethanol was removed from the extracts under vacuum condition to yield ethanol crude extracts.

2.3. The Experimental Protocols. All animals were randomly divided into five experimental groups ( $n=6$ /group) as follows: (1) the control group, animals received only vehicle; (2) LPS+vehicle; (3) LPS+Z. cassumunar $50 \mathrm{mg} / \mathrm{kg}$ body weight (BW); (4) LPS $+Z$. cassumunar $100 \mathrm{mg} / \mathrm{kg} \mathrm{BW}$, and (5) LPS +Z. cassumunar $200 \mathrm{mg} / \mathrm{kg} \mathrm{BW}$. Animals were given $1 \%$ of carboxymethyl cellulose (CMC) used as vehicle or the extract of $Z$. cassumunar (at doses of 50, 100, or $200 \mathrm{mg} / \mathrm{kg} \mathrm{BW}$ ) via oral gavage once daily for 14 days before LPS injection. LPS from Escherichia coli (strain 0111:B4, Sigma-Aldrich, St. Louis, MO, USA) was dissolved in $0.9 \%$ sterile saline. After training for the object recognition test (day 14), the animals received immediately a single intraperitoneal injection of LPS $(250 \mu \mathrm{g} / \mathrm{kg})$. The dose of LPS used was chosen based on the previous study [32]. For all animals, body weight, food, and water consumption both before and $24 \mathrm{~h}$ post-LPS administration to confirm the efficacy of LPS-induced sickness behavior were monitored. The behavioral tests were also measured $24 \mathrm{~h}$ before and following the injection of LPS. Twenty-four hours after the behavioral tests, all animals were sacrificed for immunohistochemical study (Figure 1).

2.4. Tissue Processing and Immunohistochemistry. All animals were deeply anesthetized via intraperitoneal injection of sodium pentobarbital $(70 \mathrm{mg} / \mathrm{kg}$ BW) and transcardially perfused with ice cold $0.1 \mathrm{M}$ PBS for $5 \mathrm{~min}$ followed by ice cold $4 \%$ paraformaldehyde ( $\mathrm{pH} 7.4$ ) for $15 \mathrm{~min}$. Brains were removed and postfixed overnight with the same fixative. Then, brains were placed into $12.5 \%$ sucrose for cryoprotection. Brains were sectioned into $30 \mu \mathrm{m}$ using a cryostat microtome (AST500, Amos Scientific) and stored in an antifreeze solution $\left(4^{\circ} \mathrm{C}\right)$ for immunoperoxidase labeling. Coronal sections were rinsed and incubated in $3 \% \mathrm{H}_{2} \mathrm{O}_{2}$ and followed by $3 \%$ normal horse serum for nonspecific blocking. Then, sections were incubated with primary antibody; mouse anti-glial fibrillary acidic protein (GFAP, $1: 1000$, Millipore, USA) or rabbit anti-IL-1 $\beta$ (IL- $1 \beta$, $1: 100$; Millipore, USA) at $4^{\circ} \mathrm{C}$ overnight. Sections were washed in $0.1 \mathrm{M}$ PBS for $30 \mathrm{~min}$ and incubated for $2 \mathrm{~h}$ at room temperature with biotinylated donkey anti-mouse secondary antibody or biotinylated donkey anti-rabbit ( $1: 500$, Jackson Immunoresearch, USA). Sections were rinsed and followed by an hour incubation in $0.1 \%$ extravidin peroxidase ( $1: 1000$, Sigma-Aldrich, St. Louis, MO, USA), and then rinsed again. Immunolabeling was developed using a nickelenhanced $3,3^{\prime}$-diaminobenzidine (DAB) reaction. Finally, sections were washed and then mounted on positive slides, dehydrated using graded alcohols (70, 95, and 100\% for $1 \mathrm{~min}$ each), cleared in xylene for $3 \mathrm{~min}$, and cover slipped using DPX mountant (Fisher Scientific, UK). For cresyl violet staining, sections were stained with $0.2 \%$ cresyl violet (Sigma-Aldrich, St. Louis, MO, USA), dehydrated through an ethanol series $(70,95$, and $100 \% 2 x)$, cleared in xylene, and cover slipped using DPX.

2.5. Thresholding and Cell Count Analysis. Hippocampal images (-3.14 mm from Bregma) were captured at 20x using a bright-field microscope (Olympus). The immunoreactivity signal was determined using ImageJ software. The images were cropped into 4 subregions of the hippocampus including CA1, CA2, CA3, and the dentate gyrus (DG). These cropped regions were thresholded, and the data were presented as the percentage of thresholded area. To determine the density of the neuron, $40 \mathrm{x}$ images of subregions of the hippocampus were exhaustive manual counts by using SXView program.

2.6. Novel Object Recognition Test (NORT). The novel object recognition test was performed in a black plastic apparatus (45 cm width $\times 65 \mathrm{~cm}$ length $\times 45 \mathrm{~cm}$ height $)$ with a constant light condition (40 lux). The test consisted of $5 \mathrm{~min}$ three sessions: habituation, training, and testing as previously described [33]. All animals were habituated to the empty 


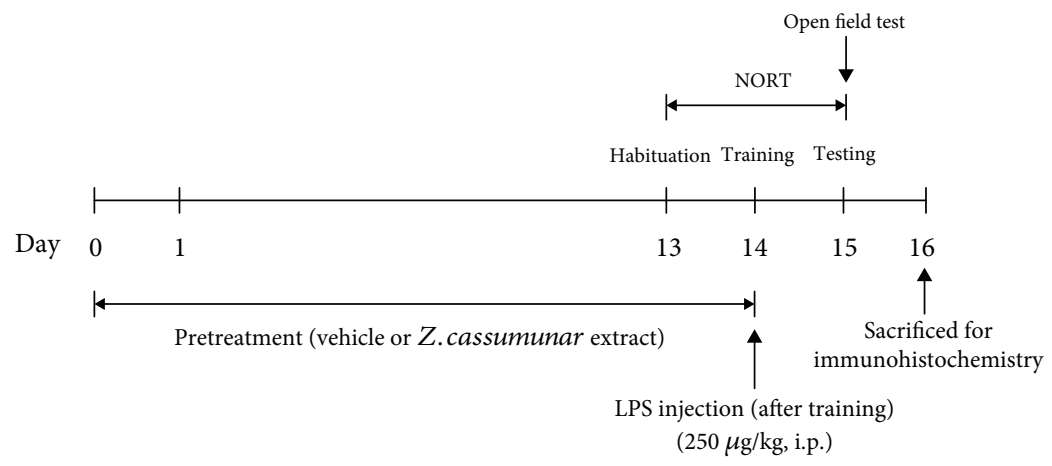

FIGURE 1: Experimental protocol and schedule of animal tests. NORT: novel object recognition test; LPS: lipopolysaccharide.

apparatus for $5 \mathrm{~min}$ and then returned to their home cage. On the training day, animals were placed into the apparatus to explore two familiar objects (object A) which was placed in the symmetrical corner of the apparatus for $5 \mathrm{~min}$. Twenty-four hours after training, the animals were allowed to investigate the objects in which one of the familiar objects was replaced by a novel object (B). The exploration time identified as pointing the nose to the object at a distance $\leq 2 \mathrm{~cm}$ was recorded. The discrimination index was determined for recognition memory, calculated as the difference of time spent exploring the novel (B) and the familiar (A) object multiplied by 100 divided by the sum of time spent exploring the novel object (B) and the familiar object (A). The box and the objects were cleaned thoroughly with $70 \%$ ethanol after each animal finished to avoid perturbation of the animals due to urine and feces. Animals showing a total exploration time $<10 \mathrm{~s}$ were excluded. Sitting or climbing on the object was not measured as exploration.

2.7. Open Field. To determine the locomotor activity, the animals were placed in the center of $45 \times 65 \times 45 \mathrm{~cm}$ apparatus following the novel object recognition task. The floor of the apparatus was divided into 16 squares. The animals were allowed to explore the field for $5 \mathrm{~min}$. The locomotor activity was assessed by testing the number of lines crossings over a $5 \mathrm{~min}$ period [34].

2.8. Statistical Analysis. All data were analyzed using GraphPad Prism 8 (GraphPad Software, USA). Data were expressed as the mean \pm S.E.M. Statistical analysis was performed using one-way ANOVA, followed by Tukey's post hoc test for multiple comparisons. $p<0.05$ was considered statistically significant.

\section{Results}

3.1. Effect of Z. cassumunar on Body Weight, Food Intake, and Locomotor Activity in LPS-Induced Sickness Behavior. The administration of LPS is a well-characterized model for neuroinflammation. Twenty-four hours after the injection, the body weight, food intake, and locomotor activity were determined. In this study, we found that a single injection of LPS at a dose of $250 \mu \mathrm{g} / \mathrm{kg}$ induced sickness-like behavior. LPS-treated animals demonstrated a significant reduction of body weight (Figure 2(a)) and food intake (Figure 2(b)) compared to the control animals $(p<0.001)$. The locomotor activity was determined by testing the number of crossings in the open field test. It was reported that LPS also significantly disturbed the locomotor activity of animals after the injection when compared to the control group $(p<0.05)$ (Figure 2(c)). However, the extract of $Z$. cassumunar at various doses $(50,100$, and $200 \mathrm{mg} / \mathrm{kg}$ ) was not able to prevent LPS-induced sickness-like behavior.

3.2. Effect of $Z$. cassumunar on Recognition Memory. In this part, the novel object recognition test was used to determine whether $Z$. cassumunar could reverse LPS-induced recognition impairment (Figure 3). The animals that received LPS showed memory impairment in long-term memory retention (delay $24 \mathrm{~h}$ ) by decreasing the discrimination index compared to the control animals $(p<0.01)$. However, all doses of $Z$. cassumunar extract tended to increase the discrimination index $(p=0.079, p=0.062$, and $p=0.058$, respectively) but did not improve recognition impairment induced by LPS, as observed by the fact that there were no significant differences between groups in exploration time with the novel object.

3.3. Effect of $Z$. cassumunar on Neuronal Density in the Hippocampus. We also investigated the effect of $Z$. cassumunar on neuronal density was detected by the cresyl violet staining of Nissl bodies (Figure 4(a)). The data demonstrated that LPS administration significantly decreased the neuronal density in all subregions of the hippocampus. Interestingly, the extract of $Z$. cassumunar at a dose of $200 \mathrm{mg} / \mathrm{kg}$ significantly prevented the neuronal cell loss in CA1 and CA3 regions of the hippocampus compared to the LPS+vehicle group (CA1; $p<0.01$, Figure $4(\mathrm{~b})$ and CA3; $p<0.05$ Figure 4(d)).

3.4. Effect of Z. cassumunar on the Immunoreactivity of GFAP in the Hippocampus. In response to LPS-induced neuroinflammation, astrocyte activation was implicated as one of the primary responders to the inflammatory process associated with brain damage. We further examined the effect of $Z$. cassumunar on the expression of GFAP (a marker of astrocyte activation) in the hippocampus. As the results show (Figure 5), immunohistochemical labeling of GFAP assessed via threshold analysis demonstrated a significant upregulation of GFAP expression in all regions of the 


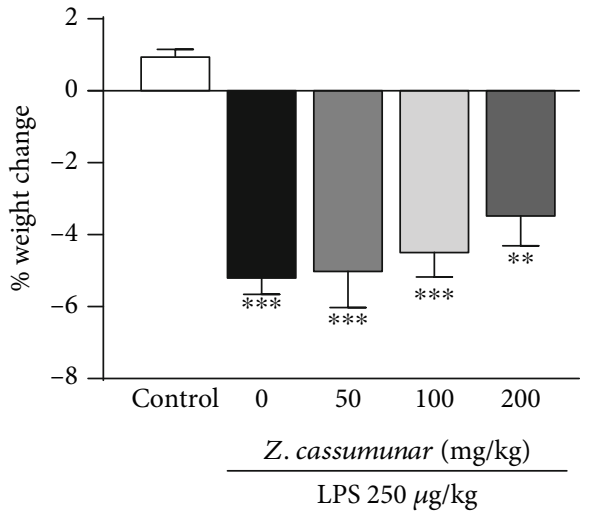

(a)

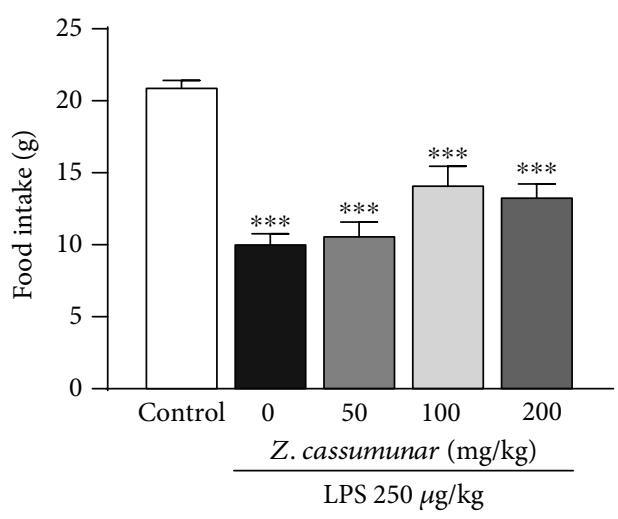

(b)

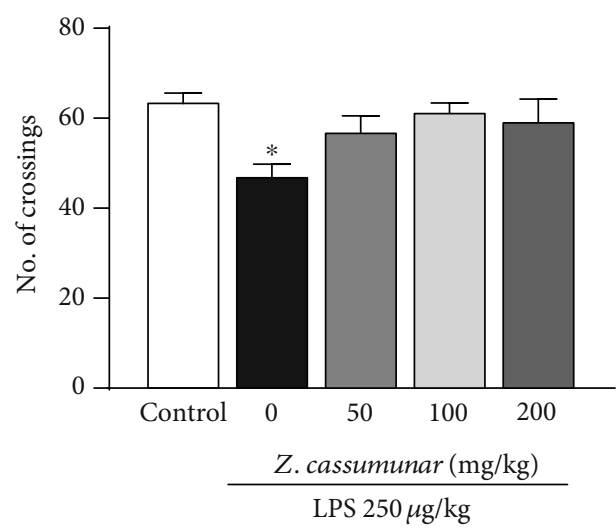

(c)

Figure 2: Effect of Z. cassumunar on body weight, food intake, and locomotor activity. LPS-treated animals showed a significant reduction of body weight (a), food intake, (b) and the number of line crossings in the open field (c). Treatments with $Z$. cassumunar did not affect body weight, food intake, and locomotor activity. Data were expressed as the mean $\pm \operatorname{SEM}(n=6) .{ }^{*} p<0.05,{ }^{* *} p<0.01$, and ${ }^{* * *} p<0.001$ vs. the control group.

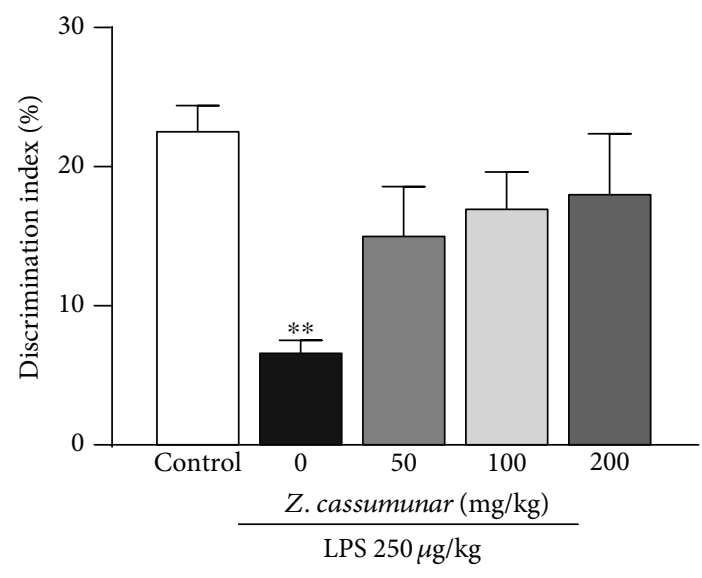

FiguRE 3: Effect of Z. cassumunar on the recognition memory in the novel object recognition test. LPS-treated animals showed the impairment of recognition memory by a reduction of the discrimination index. The extract of $Z$. cassumunar did not improve memory impairment induced by LPS. Data were expressed as the mean $\pm \operatorname{SEM}(n=6) .{ }^{* *} p<0.01$ vs. the control group. hippocampus following LPS injection (Figures 5(b)-5(e)). However, we found that pretreatment with $Z$. cassumunar extract at medium and high doses (100 and $200 \mathrm{mg} / \mathrm{kg}$ ) markedly attenuated LPS-induced overexpression of astrocytes particularly in the CA3 and DG regions of the hippocampus compared with the vehicle LPS-treated group $(p<0.05)$.

3.5. Effect of $Z$. cassumunar on the Immunoreactivity of IL-1 $\beta$ in the Hippocampus. As IL- $1 \beta$ is an important proinflammatory cytokine in the brain, we next investigated whether $Z$. cassumunar extract could modulate IL- $1 \beta$ expression within the hippocampus by using immunohistochemistry staining. Treatment with LPS significantly increased the immunoreactivity of IL- $1 \beta$ in all subregions of the hippocampus when compared to the control group $(p<0.001$; Figure 6). Pretreatment of $Z$. cassumunar at a dose of $100 \mathrm{mg} / \mathrm{kg}$ markedly decreased the expression of IL- $1 \beta$ in CA1 and DG of the hippocampus $(p<0.05, p<0.01$; Figures $6(\mathrm{a})$ and 6(d), respectively). Additionally, the extract of $Z$. cassumunar at a dose of $200 \mathrm{mg} / \mathrm{kg}$ significantly reduced the upregulation of IL- $1 \beta$ in CA1, CA3, and DG of the hippocampus $(p<0.01, p<0.05$, and $p<0.01$; Figures $6(\mathrm{a}), 6(\mathrm{c})$, and $6(d)$, respectively). 


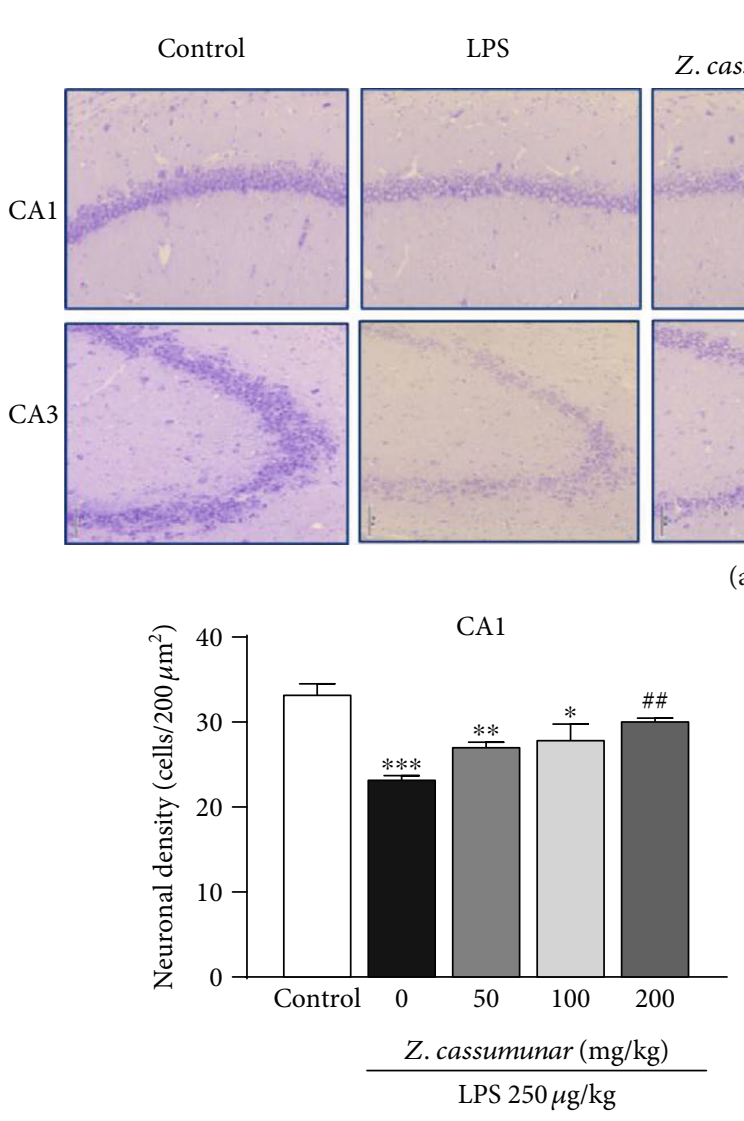

(b)

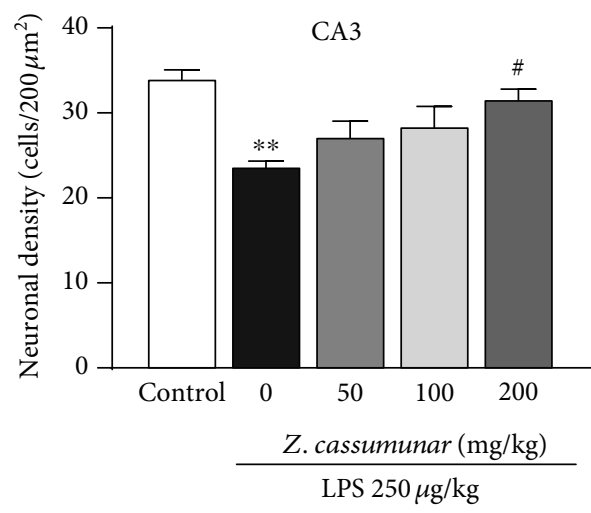

(d)
LPS+ Z. cassumunar 50

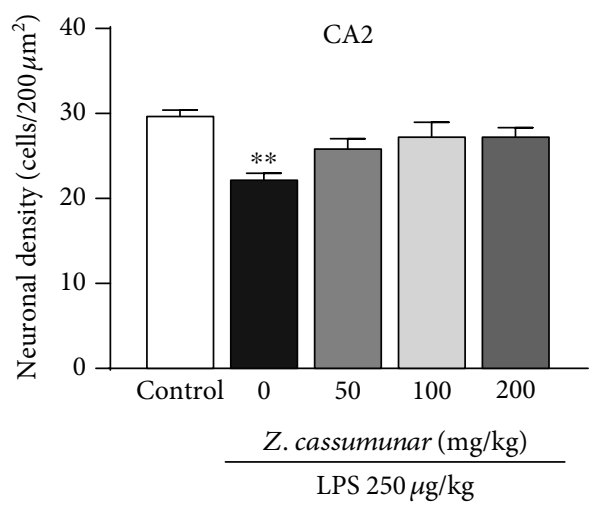

(c)

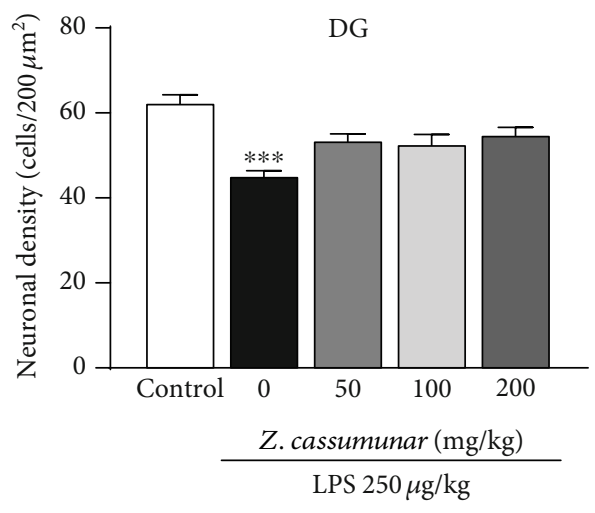

(e)

FIGURE 4: Effect of Z. cassumunar on neuronal density in the hippocampus. Representative images of CA1 and CA3 histologically stained with cresyl violet at 20x magnification (a). Graphs showed neuronal density in the hippocampus (b-e). The extract of $Z$. cassumunar significantly reversed LPS-induced neuronal cell loss in CA1 and CA3. Data were expressed as the mean $\pm \operatorname{SEM}(n=6) .{ }^{*} p<0.05,{ }^{* *} p<0.01$, and ${ }^{* * *} p$ $<0.001$ vs. the control group; ${ }^{*} p<0.05,{ }^{\# \#} p<0.01$ vs. the vehicle-treated LPS group.

\section{Discussion}

In the current study, our results suggested for the first time that pretreatment with $Z$. cassumunar extract could prevent neuronal cell loss via suppressing the activation of astrocytes and IL- $1 \beta$ in the hippocampus following the administration of LPS. LPS is a potent inducer of the inflammatory process by triggering of glial cells mainly through Toll-like receptor 4 (TLR4), which in turn produces proinflammatory cytokines, reactive oxygen species (ROS), and NO [35, 36], leading to various neurodegenerative diseases [11, 15]. Numerous studies have reported that the injection of LPS also produced memory deficit and sickness-like behavior including decreased locomotor activity, anorexia, body weight loss, increased anxiety, and somnolence $[11,18,19]$ which are considered to be very similar to the clinically important symptoms of neurodegenerative diseases in humans. Therefore, the administration of LPS is frequently used to study neuroinflammation-related neurodegenerative diseases in animals. 


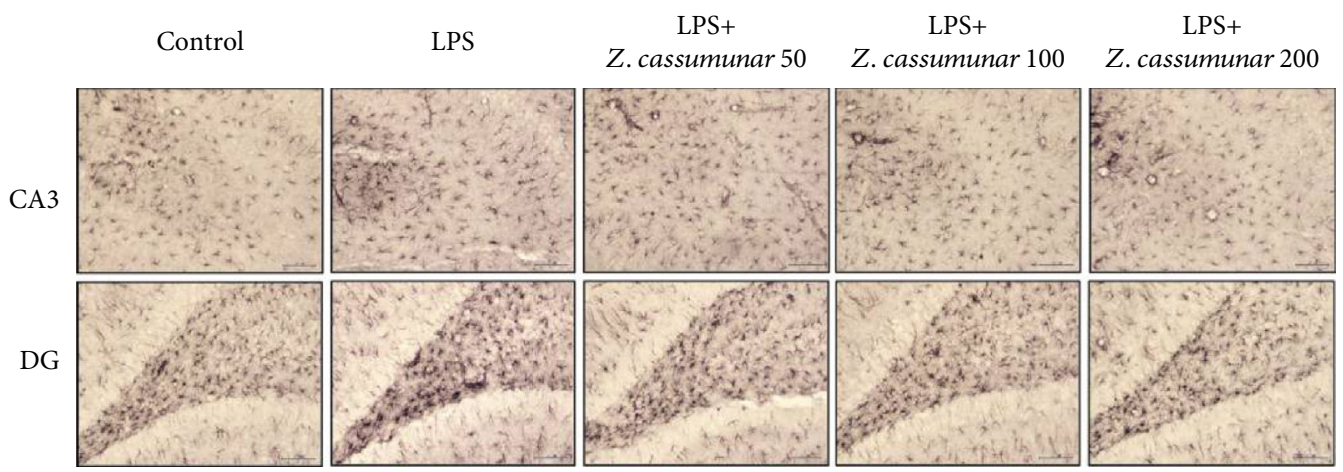

(a)

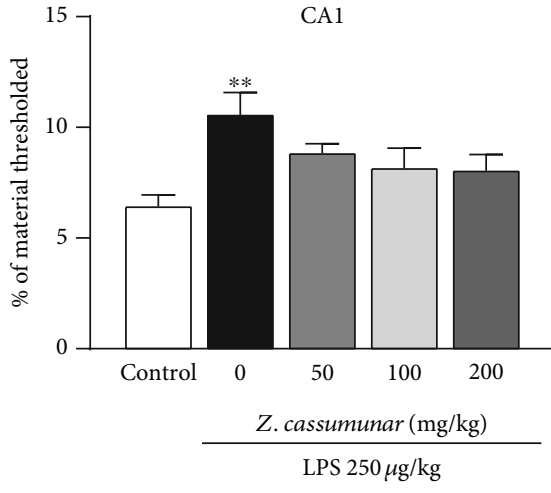

(b)

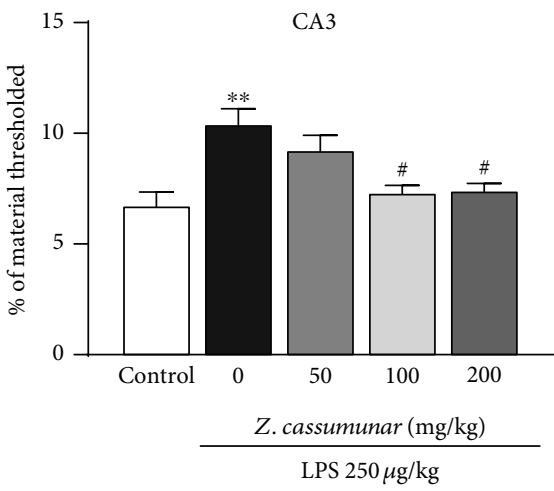

(d)

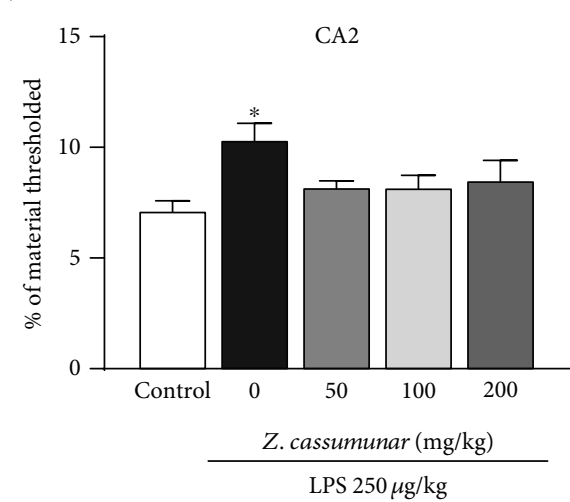

(c)

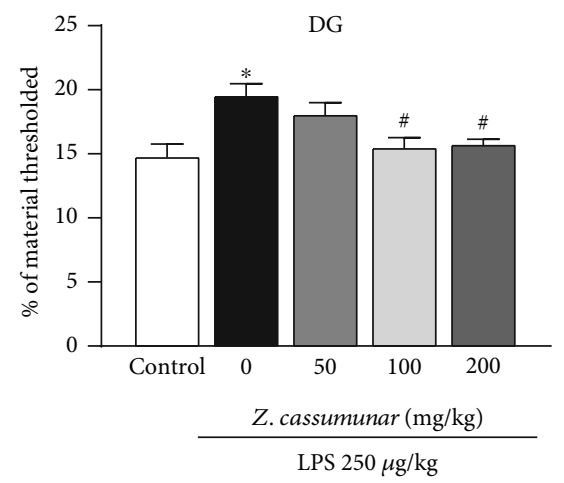

(e)

FIGURE 5: Effect of $Z$. cassumunar on the immunoreactivity of GFAP in the hippocampus. Representative images of immunohistochemical staining of GFAP in CA3 and DG (a). Graphs demonstrated the GFAP material thresholded in all subregions of the hippocampus (b-e). LPS-treated animals with $Z$. cassumunar showed a remarkable decrease in the levels of GFAP expression in CA3 and DG. Data were expressed as the mean $\pm \operatorname{SEM}(n=6) .{ }^{*} p<0.05,{ }^{* *} p<0.01$ vs. the control group; ${ }^{\#} p<0.05$ vs. the vehicle-treated LPS group.

The findings demonstrated that LPS-treated rats significantly displayed behavioral changes including decrease in body weight, food consumption, and exploratory behavior following the injection of LPS, suggesting that LPS can induce obvious sickness-like behavior in rats. However, the treatment with $Z$. cassumunar extract did not reverse the LPS-induced sickness-like behavior. As previously reported, the increase in levels of proinflammatory cytokines such as IL- $1 \alpha$, IL- $1 \beta$, TNF, and IL- 6 induced by LPS can result in sickness behavior $[12,37]$. Inflammatory cytokines within the brain can also contribute to excessive generation of free radicals correlated with behavioral impairment [38]. The sickness-like behavior is also involved in a sustained cellular reactivity in various regions of the brain including the amygdala, the hippocampus, and the hypothalamus [39]. In the present study, we only measured the expression of IL- $1 \beta$ in the hippocampus and did not measure the other proinflammatory mediators such as TNF, IL-6, and NO which are associated with the alterations of sickness-like behavior. In addition, the onset of sickness behavior due to a high dose of LPS $(250 \mu \mathrm{g} / \mathrm{kg})$ used in this study might be a crucial factor for an incomplete restoration of behavior by the treatment of extract. Thus, it is assumed that the potential effect of $Z$. cassumunar extract at the high dose $(200 \mathrm{mg} / \mathrm{kg} \mathrm{BW})$ was insufficient to improve LPS-induced sickness-like behavior via modulating of proinflammatory cytokines IL-1 $\beta$. 


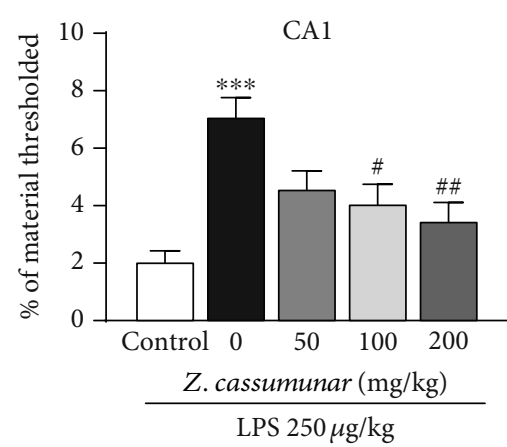

(a)

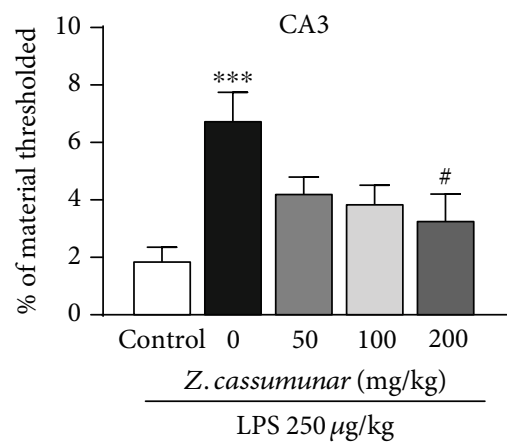

(c)

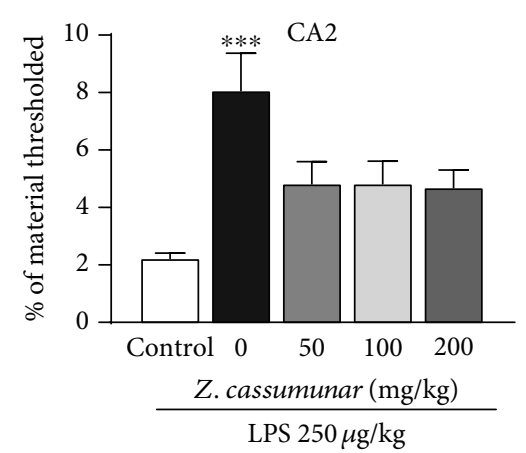

(b)

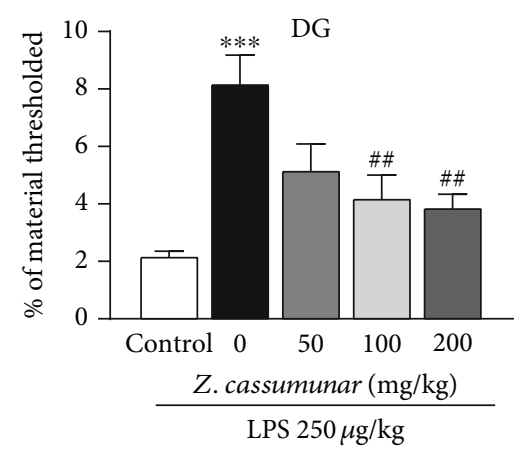

(d)

FIGURE 6: Effect of $Z$. cassumunar on the immunoreactivity of IL- $1 \beta$ in the hippocampus. Graphs demonstrated the IL- $1 \beta$ material thresholded in all subregions of the hippocampus (a-d). LPS-treated animals with $Z$. cassumunar showed a remarkable decrease in the levels of IL- $1 \beta$ expression in CA1, CA3, and DG. Data were expressed as the mean \pm SEM $(n=6) .{ }^{*} p<0.05,{ }^{* *} p<0.01$ vs. the control group; ${ }^{*} p<0.05,{ }^{\# \#} p<0.01$ vs. the vehicle-treated LPS group.

Moreover, our results revealed that LPS also has the potential to induce recognition deficit by decreasing the discrimination index in the novel object recognition test. However, pretreatment with $Z$. cassumunar at various doses was not able to significantly improve recognition memory after a $24 \mathrm{~h}$ retention interval. Previous studies have reported that the animals usually explore the new objects longer than the familiar objects when the interval between the training trial and the test trial is $1 \mathrm{~h}$ or less. The animals cannot recognize the familiar and the new objects during longer retention $[40,41]$. However, our result reported that the cognition impairment in long-term memory is not reversed by Z. cassumunar pretreatment which may relate to the incomplete recovery of the hippocampus damage from LPS-induction.

As neuroinflammation, the activation of astrocytes is stated to be a key factor in the pathophysiology of neurodegeneration $[9,42]$. There is evidence that the increased expression of GFAP, a vital protein in the astrocyte cytoskeleton, represents astrocyte activation [43]. Additionally, it has also been suggested that GFAP is important for the interaction of astrocytes and neurons and plays a crucial role in regulating synaptic function in the CNS [44]. Furthermore, previous studies have revealed that the modulation of astroglial activation can regulate neuronal survival and cognition $[45,46]$. Therefore, in this study, we focused on the protective effect of $Z$. cassumunar particularly the alterations of neurons and astrocytes in the hippocampus associated with cognitive function. The present data demonstrated that the peripheral LPS administration significantly decreased the neuronal density in all subregions of the hippocampus when compared to the control group. Z. cassumunar extract at a dose of $200 \mathrm{mg} / \mathrm{kg}$ was effective against the neuronal cell loss in the CA1 and CA3 regions of the hippocampus. As previously reported, the hippocampus can be affected by several pathological conditions such as ischemia, inflammation, and oxidative stress [47]. It has been also suggested that CA1 and CA3 importantly contribute a crucial role in the memory process $[48,49]$. Upon activation, astrocytes generally alter their morphology for being hypertrophic and express an increased expression of GFAP [50]. This study reported that LPS induction significantly increased the immunoreactivity of GFAP in the hippocampus, while pretreatment with Z. cassumunar ( 100 and $200 \mathrm{mg} / \mathrm{kg}$ ) was able to suppress the expression of GFAP in the hippocampus particularly in CA3 and DG. Several investigations have suggested that increased expression of GFAP is associated with the excessive production of proinflammatory substances such as IL- $1 \beta$, TNF- $\alpha$, and NO $[51,52]$. IL- $1 \beta$ is a pleiotropic cytokine family, which is involved in acute neuroinflammation-related diseases [53]. IL-1 $\beta$ is mainly produced by microglia and astrocytes $[54,55]$. The present study showed that LPS injection significantly elevated the expression of proinflammatory cytokine IL- $1 \beta$ in the hippocampus, while $Z$. cassumunar extract at a dose of $200 \mathrm{mg} / \mathrm{kg}$ BW significantly reduced the expression of IL$1 \beta$ in CA1, CA3, and DG. Thus, the results indicated that 
pretreatment with $Z$. cassumunar can increase neuronal density through the inhibition of the expression of GFAP and IL-1 $\beta$ in the hippocampus. The possible mechanisms of reduced neuronal cell loss might be involved in antiinflammatory and antioxidant activities of the extract by suppressing astroglial activation-induced IL- $1 \beta$ production. Evidence from a previous study has reported that isolated phenylbutanoids from $Z$. cassumunar rhizomes have antiinflammatory activity by the inhibition of LPS-induced NO production in mouse peritoneal macrophages [56]. Additionally, phenylbutanoid, E-4-( $3^{\prime}, 4^{\prime}$-dimethoxyphenyl)but-3-en1-ol, from $Z$. cassumunar exhibited anti-inflammatory effect in rats. However, isolated chemical active ingredients from $Z$. cassumunar have not been determined for neuroprotective activity in the animal models. Considering neuroprotective effects of active compound from a medicinal plant that is closely related to $Z$. cassumunar, gingerol from $Z$. officinale exerts neuroprotective effects against oxidative stress-related neurodegeneration $[57,58]$. Recently, it has been reported that gingerol decreases LPS-induced neuroinflammation and cognitive impairment through inhibiting astrocyte overactivation in rats [59].

To our knowledge, this is the first study demonstrating the neuroprotective effects of $Z$. cassumunar extract on the neuronal cell loss via suppressing the overactivation of astrocytes. The important limitations of this study are the lack of the identification of bioactive ingredients and relevant molecular mechanisms of beneficial effects. However, since we now demonstrated the neuroprotective activity of $Z$. cassumunar crude extract against neuronal damage and neuroinflammation, we recommend that further investigations of the main bioactive compounds are required to provide better understanding concerning the neuroprotective effects.

\section{Conclusions}

In conclusion, intraperitoneal injection of LPS-induced neuronal cell loss caused an inflammatory response by activating the astrocytes and increasing the expression of proinflammatory cytokine IL- $1 \beta$ in the hippocampus. Pretreatment with $Z$. cassumunar crude extract attenuated LPS-induced neuronal cell loss by reducing the expression of GFAP and IL- $1 \beta$ in the hippocampus. Therefore, the present study suggested that $Z$. cassumunar crude extract might be a potential neuroprotective agent for the treatment of LPS-induced neurodegenerative diseases.

\section{Data Availability}

The data used to support the findings of this study are included within the article.

\section{Conflicts of Interest}

The authors declare that they have no conflicts of interest.

\section{Acknowledgments}

We would like to thank Assistant Professor Dr. Serm Surapinit for preparing the extract. This study was financially supported by the University of Phayao, Muang, Phayao, Thailand (grant no. RD62060).

\section{References}

[1] V. W. Yong, "Inflammation in neurological disorders: a help or a hindrance?," The Neuroscientist, vol. 16, no. 4, pp. 408420, 2010.

[2] M. D. Nguyen, J. P. Julien, and S. Rivest, "Innate immunity: the missing link in neuroprotection and neurodegeneration?," Nature Reviews. Neuroscience, vol. 3, no. 3, pp. 216-227, 2002.

[3] D. J. Allison and D. S. Ditor, "The common inflammatory etiology of depression and cognitive impairment: a therapeutic target," Journal of Neuroinflammation, vol. 11, no. 1, p. 151, 2014.

[4] T. Benton, J. Staab, and D. L. Evans, "Medical co-morbidity in depressive disorders," Annals of Clinical Psychiatry, vol. 19, no. 4, pp. 289-303, 2007.

[5] P. L. McGeer, S. Itagaki, B. E. Boyes, and E. G. McGeer, "Reactive microglia are positive for HLA-DR in the substantia nigra of Parkinson's and Alzheimer's disease brains," Neurology, vol. 38, no. 8, pp. 1285-1291, 1988.

[6] Y. Dong and E. N. Benveniste, "Immune function of astrocytes," Glia, vol. 36, no. 2, pp. 180-190, 2001.

[7] D. Brites and A. Fernandes, "Neuroinflammation and depression: microglia activation, extracellular microvesicles and microRNA dysregulation," Frontiers in Cellular Neuroscience, vol. 9, p. 476, 2015.

[8] A. Khan, T. Ali, S. U. Rehman et al., "Neuroprotective effect of quercetin against the detrimental effects of LPS in the adult mouse brain," Frontiers in Pharmacology, vol. 9, p. 1383, 2018.

[9] P. Agostinho, R. A. Cunha, and C. Oliveira, "Neuroinflammation, oxidative stress and the pathogenesis of Alzheimer's disease," Current Pharmaceutical Design, vol. 16, no. 25, pp. 2766-2778, 2010.

[10] B. Liu and J. S. Hong, "Role of microglia in inflammationmediated neurodegenerative diseases: mechanisms and strategies for therapeutic intervention," The Journal of Pharmacology and Experimental Therapeutics, vol. 304, no. 1, pp. 1-7, 2003.

[11] J. Zhao, W. Bi, S. Xiao et al., "Neuroinflammation induced by lipopolysaccharide causes cognitive impairment in mice," Scientific Reports, vol. 9, no. 1, p. 5790, 2019.

[12] R. Dantzer, J. C. O'Connor, G. G. Freund, R. W. Johnson, and K. W. Kelley, "From inflammation to sickness and depression: when the immune system subjugates the brain," Nature Reviews. Neuroscience, vol. 9, no. 1, pp. 46-56, 2008.

[13] C. R. A. Batista, G. F. Gomes, E. Candelario-Jalil, B. L. Fiebich, and A. C. P. de Oliveira, "Lipopolysaccharide-induced neuroinflammation as a bridge to understand neurodegeneration," International Journal of Molecular Sciences, vol. 20, no. 9, p. 2293, 2019.

[14] J. W. Lee, Y. K. Lee, D. Y. Yuk et al., "Neuro-inflammation induced by lipopolysaccharide causes cognitive impairment through enhancement of beta-amyloid generation," Journal of Neuroinflammation, vol. 5, no. 1, p. 37, 2008. 
[15] L. Qin, X. Wu, M. L. Block et al., "Systemic LPS causes chronic neuroinflammation and progressive neurodegeneration," Glia, vol. 55, no. 5, pp. 453-462, 2007.

[16] Q. P. Han, Q. Y. Lin, P. X. Huang et al., "Microglia-derived IL$1 \beta$ contributes to axon development disorders and synaptic deficit through p38-MAPK signal pathway in septic neonatal rats," Journal of Neuroinflammation, vol. 14, no. 1, p. 52, 2017.

[17] K. N. Shaw, S. Commins, and S. M. O'Mara, "Lipopolysaccharide causes deficits in spatial learning in the watermaze but not in BDNF expression in the rat dentate gyrus," Behavioural Brain Research, vol. 124, no. 1, pp. 47-54, 2001.

[18] D. Y. Choi, J. W. Lee, G. Lin et al., "Obovatol attenuates LPSinduced memory impairments in mice via inhibition of NF- $\kappa \mathrm{B}$ signaling pathway," Neurochemistry International, vol. 60, no. 1, pp. 68-77, 2012.

[19] J. C. O'Connor, M. A. Lawson, C. André et al., "Lipopolysaccharide-induced depressive-like behavior is mediated by indoleamine 2,3-dioxygenase activation in mice," Molecular Psychiatry, vol. 14, no. 5, pp. 511-522, 2009.

[20] C. J. Henry, Y. Huang, A. Wynne et al., "Minocycline attenuates lipopolysaccharide (LPS)-induced neuroinflammation, sickness behavior, and anhedonia," Journal of Neuroinflammation, vol. 5, no. 1, p. 15, 2008.

[21] A. M. Waggas, "Neuroprotective evaluation of extract of ginger (Zingiber officinale) root in monosodium glutamateinduced toxicity in different brain areas male albino rats," Pakistan Journal of Biological Sciences, vol. 12, no. 3, pp. 201-212, 2009.

[22] C. Sutalangka and J. Wattanathorn, "Neuroprotective and cognitive-enhancing effects of the combined extract of Cyperus rotundus and Zingiber officinale," BMC Complementary and Alternative Medicine, vol. 17, no. 1, p. 135, 2017.

[23] X. Yang, T. Zheng, H. Hong et al., "Neuroprotective effects of Ginkgo biloba extract and ginkgolide B against oxygen-glucose deprivation/reoxygenation and glucose injury in a new in vitro multicellular network model," Frontiers in Medicine, vol. 12, no. 3, pp. 307-318, 2018.

[24] W. Y. Ong, T. Farooqui, H. L. Koh, A. A. Farooqui, and E. A. Ling, "Protective effects of ginseng on neurological disorders," Frontiers in Aging Neuroscience, vol. 7, p. 129, 2015.

[25] J. R. Sundaram, C. P. Poore, N. H. B. Sulaimee et al., "Curcumin ameliorates neuroinflammation, neurodegeneration, and memory deficits in p25 transgenic mouse model that bears hallmarks of Alzheimer's disease," Journal of Alzheimer's Disease, vol. 60, no. 4, pp. 1429-1442, 2017.

[26] C. Fan, Q. Song, P. Wang, Y. Li, M. Yang, and S. Y. Yu, "Neuroprotective effects of curcumin on IL- $1 \beta$-induced neuronal apoptosis and depression-like behaviors caused by chronic stress in rats," Frontiers in Cellular Neuroscience, vol. 12, p. 516, 2019.

[27] N. R. Farnsworth and N. Bunyapraphatsara, Thai Medicinal Plants: Recommended for Primary Health Care System, Prachachon, Bangkok, Thailand, 1992.

[28] R. Jeenapongsa, K. Yoovathaworn, K. M. Sriwatanakul, U. Pongprayoon, and K. Sriwatanakul, "Anti-inflammatory activity of (E)-1-(3,4-dimethoxyphenyl) butadiene from Zingiber cassumunar Roxb.," Journal of Ethnopharmacology, vol. 87, no. 2-3, pp. 143-148, 2003.

[29] S. Bua-in and Y. Paisooksantivatana, "Essential oil and antioxidant activity of cassumunar ginger (Zingiberaceae: Zingiber montanum (Koenig) Link ex Dietr.) collected from various parts of Thailand," Kasetsart Journal-Natural Science, vol. 43, pp. 467-475, 2009.

[30] S. Tewtrakul and S. Subhadhirasakul, "Anti-allergic activity of some selected plants in the Zingiberaceae family," Journal of Ethnopharmacology, vol. 109, no. 3, pp. 535-538, 2007.

[31] N. Wong-a-nan, K. Inthanon, A. Saiai et al., "Lipogenesis inhibition and adipogenesis regulation via PPAR $\gamma$ pathway in 3T3-L1 cells byZingiber cassumunarRoxb.rhizome extracts," Egyptian Journal of Basic and Applied Sciences, vol. 5, no. 4, pp. 289-297, 2019.

[32] M. S. Khan, T. Ali, M. N. Abid et al., "Lithium ameliorates lipopolysaccharide-induced neurotoxicity in the cortex and hippocampus of the adult rat brain," Neurochemistry International, vol. 108, pp. 343-354, 2017.

[33] J. Lin, L. Huang, J. Yu et al., "Fucoxanthin, a marine carotenoid, reverses scopolamine-induced cognitive impairments in mice and inhibits acetylcholinesterase in vitro," Marine Drugs, vol. 14, no. 4, p. 67, 2016.

[34] A. H. Swiergiel and A. J. Dunn, "Effects of interleukin- $1 \beta$ and lipopolysaccharide on behavior of mice in the elevated plusmaze and open field tests," Pharmacology, Biochemistry, and Behavior, vol. 86, no. 4, pp. 651-659, 2007.

[35] R. E. Mrak and W. S. T. Griffin, "Glia and their cytokines in progression of neurodegeneration," Neurobiology of Aging, vol. 26, no. 3, pp. 349-354, 2005.

[36] T. Kielian, "Toll-like receptors in central nervous system glial inflammation and homeostasis," Journal of Neuroscience Research, vol. 83, no. 5, pp. 711-730, 2006.

[37] R. Dantzer, "Cytokine, sickness behavior, and depression," Immunology and Allergy Clinics of North America, vol. 29, no. 2, pp. 247-264, 2009.

[38] H. A. Mansour, W. A. Hassan, and G. S. Georgy, "Neuroinflammatory reactions in sickness behavior induced by bacterial infection: protective effect of minocycline," Journal of Biochemical and Molecular Toxicology, vol. 32, no. 2, 2018.

[39] C. Bay-Richter, S. Janelidze, L. Hallberg, and L. Brundin, "Changes in behaviour and cytokine expression upon a peripheral immune challenge," Behavioural Brain Research, vol. 222, no. 1, pp. 193-199, 2011.

[40] O. Deschaux, J. C. Bizot, and M. Goyffon, “Apamin improves learning in an object recognition task in rats," Neuroscience Letters, vol. 222, no. 3, pp. 159-162, 1997.

[41] C. Puma and J. C. Bizot, "Intraseptal infusions of a low dose of AP5, a NMDA receptor antagonist, improves memory in an object recognition task in rats," Neuroscience Letters, vol. 248, no. 3, pp. 183-186, 1998.

[42] P. J. Khandelwal, A. M. Herman, and C. E.-H. Moussa, "Inflammation in the early stages of neurodegenerative pathology," Journal of Neuroimmunology, vol. 238, no. 1-2, pp. 1-11, 2011.

[43] E. M. Hol and M. Pekny, "Glial fibrillary acidic protein (GFAP) and the astrocyte intermediate filament system in diseases of the central nervous system," Current Opinion in Cell Biology, vol. 32, pp. 121-130, 2015.

[44] K. Shibuki, H. Gomi, L. Chen et al., "Deficient cerebellar longterm depression, impaired eyeblink conditioning, and normal motor coordination in GFAP mutant mice," Neuron, vol. 16, no. 3, pp. 587-599, 1996.

[45] S. K. Madathil, S. W. Carlson, J. M. Brelsfoard, P. Ye, A. J. D'Ercole, and K. E. Saatman, “Astrocyte-specific overexpression of insulin-like growth factor-1 protects hippocampal 
neurons and reduces behavioral deficits following traumatic brain injury in mice," PLoS One, vol. 8, no. 6, article e67204, 2013.

[46] M. R. Hoane, S. L. Akstulewicz, and J. Toppen, "Treatment with vitamin B3 improves functional recovery and reduces GFAP expression following traumatic brain injury in rats," Journal of Neurotrauma, vol. 20, no. 11, pp. 1189-1199, 2003.

[47] T. Bartsch, J. Döhring, S. Reuter et al., "Selective neuronal vulnerability of human hippocampal CA1 neurons: lesion evolution, temporal course, and pattern of hippocampal damage in diffusion-weighted MR imaging," Journal of Cerebral Blood Flow and Metabolism, vol. 35, no. 11, pp. 1836-1845, 2015.

[48] J. Ji and S. Maren, "Differential roles for hippocampal areas CA1 and CA3 in the contextual encoding and retrieval of extinguished fear," Learning \& Memory, vol. 15, no. 4, pp. 244-251, 2008.

[49] E. Cherubini and R. Miles, "The CA3 region of the hippocampus: how is it? What is it for? How does it do it?," Frontiers in Cellular Neuroscience, vol. 9, 2015.

[50] M. V. Sofroniew and H. V. Vinters, "Astrocytes: biology and pathology," Acta Neuropathologica, vol. 119, no. 1, pp. 7-35, 2010.

[51] S. Brahmachari, Y. K. Fung, and K. Pahan, "Induction of glial fibrillary acidic protein expression in astrocytes by nitric oxide," The Journal of Neuroscience, vol. 26, no. 18, pp. 4930-4939, 2006.

[52] J.-B. Kang, D.-J. Park, M.-A. Shah, M.-O. Kim, and P.-O. Koh, "Lipopolysaccharide induces neuroglia activation and NF- $\kappa \mathrm{B}$ activation in cerebral cortex of adult mice," Laboratory Animal Research, vol. 35, no. 1, p. 19, 2019.

[53] S. S. Shaftel, W. S. Griffin, and M. K. O'Banion, "The role of interleukin-1 in neuroinflammation and Alzheimer disease: an evolving perspective," Journal of Neuroinflammation, vol. 5, no. 1, p. 7, 2008.

[54] G. A. Higgins and J. A. Olschowka, "Induction of interleukin$1 \beta$ mRNA in adult rat brain," Brain Research. Molecular Brain Research, vol. 9, no. 1-2, pp. 143-148, 1991.

[55] N. Rothwell, "Interleukin-1 and neuronal injury: mechanisms, modification, and therapeutic potential," Brain, Behavior, and Immunity, vol. 17, no. 3, pp. 152-157, 2003.

[56] S. Nakamura, J. Iwami, H. Matsuda, H. Wakayama, Y. Pongpiriyadacha, and M. Yoshikawa, "Structures of new phenylbutanoids and nitric oxide production inhibitors from the rhizomes of Zingiber cassumunar," Chemical \& Pharmaceutical Bulletin, vol. 57, no. 11, pp. 1267-1272, 2009.

[57] C. Lee, G. H. Park, C. Y. Kim, and J. H. Jang, "[6]-Gingerol attenuates $\beta$-amyloid-induced oxidative cell death via fortifying cellular antioxidant defense system," Food and Chemical Toxicology, vol. 49, no. 6, pp. 1261-1269, 2011.

[58] C.-Y. Kim, Y. Seo, C. Lee, G. H. Park, and J.-H. Jang, "Neuroprotective effect and molecular mechanism of [6]-gingerol against scopolamine-induced amnesia in C57BL/6 mice," Evidence-based Complementary and Alternative Medicine, vol. 2018, Article ID 8941564, 11 pages, 2018.

[59] F. Zhang, J. G. Zhang, W. Yang, P. Xu, Y. L. Xiao, and H. T. Zhang, "6-Gingerol attenuates LPS-induced neuroinflammation and cognitive impairment partially via suppressing astrocyte overactivation," Biomedicine \& Pharmacotherapy, vol. 107, pp. 1523-1529, 2018. 